\title{
Evidence-based actions for maximising training effectiveness in corporate E-learning and classroom training
}

\section{Andrea Beinicke \& Eva Kyndt}

To cite this article: Andrea Beinicke \& Eva Kyndt (2019): Evidence-based actions for maximising training effectiveness in corporate E-learning and classroom training. Studies in Continuing Education, DOI: 10.1080/0158037X.2019.1608940

To link to this article: https://doi.org/10.1080/0158037X.2019.1608940

+ View supplementary material $\widetilde{T}$

曲 Published online: 26 Apr 2019.

Submit your article to this journal $\widetilde{ }$

View Crossmark data \lceil 


\title{
Evidence-based actions for maximising training effectiveness in corporate E-learning and classroom training
}

\author{
Andrea Beinicke (D) a ${ }^{a}$ and Eva Kyndt (1) ${ }^{b}$ \\ aDepartment of Psychology, Work and Organizational Psychology, University of Würzburg, Würzburg, \\ Germany; ${ }^{\mathrm{b}}$ Occupational and Organisational Psychology and Professional Learning, KU Leuven - University of \\ Leuven, Leuven, Belgium
}

\begin{abstract}
The present study aimed at contributing to the science-practice gap regarding the application of evidence-based actions for maximising training effectiveness in corporate practice. Training and development professionals employed at companies from diverse branches of industry and among the best employers in Germany were assessed cross-sectionally regarding actions that foster transfer separately for e-learning and classroom training. Results showed that actions for maximising training effectiveness were almost always implemented in both training settings, especially before and during training. However, after training, such actions were least implemented in both training settings. Moreover, fewer actions were implemented in e-learning compared with classroom training settings before, during, and after training. Although companies implemented transfer-supportive actions to a great deal, we emphasise that there is room for improvement in corporate practice, especially in meeting the needs of older workers and evaluation training at multiple levels.
\end{abstract}

\section{ARTICLE HISTORY}

Received 14 May 2018

Accepted 10 April 2019

\section{KEYWORDS}

Training effectiveness; elearning; workplace learning; organisational learning; transfer of training

\section{Introduction}

Due to the rapid pace of many societal and technological changes in recent times, companies have recognised the importance to invest in the knowledge and skills of their employees (e.g. Hurtz and Williams 2009; Kyndt and Baert 2013). While increasing attention is being directed towards workplace- and (other forms of) informal learning, the vast majority of the budget of Human Resource Development (HRD) departments still goes to formal, instructor-led training. For example, European organisations spend an average of $1.6 \%$ of their labour costs (between $0.7 \%$ in Greece and 2.5\% in France) on training (Eurostat 2010). However, the 2017 State of the Industry report for the US stated that organisations spent an average of $\$ 1273$ per employee in 2016; in fact, this is the fourth year in a row that has seen an increase in direct learning expenditure which results in an investment of billions each year across the country (ATD Research 2017). Despite criticism on formal training, companies are still spending huge budgets on them.

CONTACT Andrea Beinicke $\otimes$ andrea.beinicke@uni-wuerzburg.de $\Theta$ Department of Psychology, Work and Organizational Psychology, University of Würzburg, Röntgenring 10, Würzburg 97070, Germany 
At the same time, many practitioners and scholars have pointed towards the limited transfer of what has been taught in formal training into actual daily practice in the workplace, and have thereby acknowledged the 'transfer problem' (e.g. Baldwin and Ford 1988; Grossman and Salas 2011; Govaerts and Dochy 2014). Prior studies indicated that only a limited amount of what has been learned is transferred to the workplace (Blume et al. 2010). For example, the transfer problem very likely occurs if the training situation differs significantly from the work situation. This effect is confirmed by several scientific studies, including meta-analyses (Grossman and Salas 2011; Saks, Salas, and Lewis 2014). Moreover, the amount of transfer declines further as time progresses from the moment of training. A survey by Saks (2002) indicated that on average, $38 \%$ of trainees reveal that they do not apply what they have learned in the training to the workplace when asked immediately after training; this rate rises to $56 \%$ after six months and 66\% after one year. According to Saks (2002), the transfer problem is even underestimated in his study due to a self-serving bias of the trainers' judgments (Podsakoff et al. 2003). Moreover, only 50\% of investments in training improve the situation of employees and the organisation (Saks 2002). Consequently, many scholars have begun investigating how transfer occurs and how it can be fostered (e.g. Blume et al. 2010; Saks and Burke 2012; Saks, Salas, and Lewis 2014; Baldwin, Ford, and Blume 2017).

The most frequently cited model of training transfer (which has received great attention in training research literature) is Baldwin and Ford's (1988) transfer process model. Their framework distinguishes between training inputs, training outputs (acquisition of knowledge and skills during training), and conditions of transfer (generalisation of knowledge and skills acquired during training for the job and the maintenance of this learning over time on the job). Focusing on training inputs, Baldwin and Ford's (1988) framework categorises factors that potentially influence the transfer of training at three levels: the individual or trainee, the training activity in terms of design and content, and the organisation or - more specifically - the trainee's work environment. From the perspective of the organisation, most attention has gone to the trainee's working environment because the management and HRD department can exert the most direct influence on factors found in this category, especially because many organisations do not have their own training department and outsource the actual training activity to external providers.

However, while prior research has been able to identify strategies that foster the transfer of training (e.g. Grossman and Salas 2011; Salas et al. 2012), little is known about actually putting these strategies into practice. As such, it is unclear whether the transfer literature is facing a transfer problem itself or whether or not current practices are evidence-based. In light of recent demands for evidence-based practices, we still need to bridge the gap between science and practice (Bell et al. 2017). One possible step in pursuing this difficult but essential demand is to inform professionals about results on the science of transfer, so that they can design and execute training initiatives more effectively (e.g. Baldwin, Ford, and Blume 2017; Ford, Baldwin, and Prasad 2018). Hence, the present study sets out to investigate whether there is a science-practice gap regarding strategies that foster transfer. More specifically, we investigate whether the actions for maximising training effectiveness identified by Salas et al. (2012) are being implemented in practice. 
As mentioned before, technological changes lie at the root of the increased attention paid to employees' professional development; however, these technological changes also influence the way trainings are being designed. While the majority of studies thus far has concentrated on face-to-face classroom changes, more and more formal trainings are being offered online via e-learning, thereby complementing or even replacing traditional classroom training (Fry 2001). As we turn our attention to what actions are taking place within trainees' working environment, we also consider the role of training design; thus zooming in on the training input factors of Baldwin and Ford's model (1988). More specifically, we examine whether there is a difference in the implementation of actions for maximising training effectiveness between classroom training and training via e-learning. In other words, we wonder if companies are adopting a differential approach when trying to increase the impact of the two different training designs.

In the following sections, we present propositions on training effectiveness by Salas et al. (2012) and introduce our main research questions (RQ). Subsequently, the present study, study setting, and methodology are discussed. After presenting the results for each RQ, findings are enumerated against the background of the science-practice gap literature. Finally, implications for practice and future directions for research are proposed.

\section{State of the art}

In order to bridge the science-practice gap, further insights on research results regarding the effective design, delivery, and implementation of trainings are needed. In the past 40 years, substantial progress in the multidisciplinary science of training theory has been achieved, and many evidence-based empirical studies have been executed (e.g. Salas and Cannon-Bowers 2001). Various meta-analytical findings with medium to large effect sizes have yielded the conclusion that training works when systematically designed based on learning theories (for a systematic overview, see Salas et al. 2012).

Scientific key results are subsumed within the framework of Salas et al. (2012). Importantly, the framework assumes that training effectiveness can be influenced in three time intervals within the training process, that is, by actions before, during, and after training. In accordance, it has been demonstrated that considering more than one measurement point in the training process is crucial (e.g. Massenberg, Schulte, and Kauffeld 2017). First, actions implemented before training play a key role in successful training effectiveness. For example, conducting a training needs analysis and the preparation of an optimal learning climate can facilitate training effectiveness. Furthermore, motivation to learn and self-efficacy beliefs before training influence motivation to transfer and self-efficacy beliefs after the training and thus training effectiveness (Massenberg, Schulte, and Kauffeld 2017).

Second, research has identified crucial actions during training, which Salas et al. (2012) have categorised as (a) enabling the 'right' mindset of trainees (e.g. building self-efficacy or boosting motivation to learn), (b) following appropriate instructional principles, and (c) using technology 'wisely'. Third, post-training activities tremendously affect the targeted transfer goal by enabling trainees to apply what they have learned to the job. For example, supervisors can support their employees by providing transfer opportunities (Govaerts et al. 2017) and removing obstacles to maintain skills. Finally, evaluating training enables effective training to be continued. Salas stated that these actions apply rather parallel to each other and are generally important. 
To improve transfer, factors significantly related to the transfer of training have been identified in a meta-analytic review (Blume et al. 2010) and also in various studies (e.g. Baldwin, Ford, and Blume 2017; Kodwani 2017). Overall, employees, as well as organisational factors from all three levels of Baldwin and Ford's (1988) model, were found to be positively and significantly related to (perceived) training transfer. For example, training awareness, participation and involvement in training decision as trainee characteristics, training transfer climate as work environment, or training assessment mechanism as training design were detected (Kodwani 2017).

In closer detail with a basis on Baldwin and Ford's (1988) model, results revealed a positive moderate relationship between trainee characteristics and transfer, with cognitive ability as the single largest predictor of transfer. Conscientiousness, voluntary participation, neuroticism, pre-training self-efficacy, motivation to learn, and a learning goal orientation displayed moderate relationships with the transfer. Additionally, the role of employees' involvement in T\&D activities has been demonstrated, that is, creating a good learning environment, providing encouragement, and linking training more closely to work practices (Kodwani and Singh 2004).

With regard to supportive work environment factors, analyses indicated that the strongest relationship exists for transfer, transfer climate, and support. There is a stronger relationship for supervisor support compared with peer support. Regarding the role of the training design as the third training input identified by Baldwin and Ford (1988), meta-analytic studies have investigated not only overlearning (Driskell, Willis, and Copper 1992) and practice (Arthur et al. 1998), but also training delivery methods (Arthur et al. 2003; Sitzmann et al. 2006). Results indicated strong effects on performance gained from overlearning (Driskell, Willis, and Copper 1992), and vice versa, especially for cognitive tasks, and a substantial skill loss (over time) was found when the training content was non-practiced (Arthur et al. 1998). Further, focusing on specific points of time in the training transfer process seems crucial: Especially the time before the training takes place is important as more learning transfer system factors before the training than after the training predicted trainees' motivation to transfer (Massenberg, Schulte, and Kauffeld 2017). Differences in applied training methods are presented next.

\section{Differences between e-learning and classroom training}

In light of the fact that training settings applied in practice vary significantly across educational aims and institutions, two training settings need to be fundamentally distinguished: e-learning and classroom training. As previously mentioned, the transfer of information via e-learning settings has become more important, and companies are thus experiencing a shift from traditional classroom training to e-learning.

Statistics demonstrate that the companies that continue to innovate in corporate elearning settings are considered market leaders. For example, according to a U.S. study in $2001,80 \%$ of U.S. Fortune 500 companies had already implemented e-learning programs or planned to do so in the near future (Hammond 2001). Similarly, 55\% of the top 500 companies in Germany had implemented e-learning programs for further training in addition to traditional classroom training, with web-based training, computer-based training, and blended learning among the most implemented forms of corporate e- 
learning (MMB 2010). Up to now, e-learning settings have become a standard procedure in the corporate training context (MMB 2010; Hochholdinger and Beinicke 2012).

The current literature on the advantages and disadvantages of corporate e-learning raises the following question: Which training setting - e-learning or classroom training - is most appropriate given certain circumstances? In recent decades, several studies have addressed this question (e.g. Sitzmann et al. 2006). A meta-analysis of the effectiveness of distance education by Zhao et al. (2005) reported no significant differences in outcomes between distance and face-to-face instruction (for previous meta-analyses, see also Machtmes and Asher 2000; Cavanaugh 2001). Accordingly, a later meta-analysis by Sitzmann et al. (2006) also found no significance in outcomes. Trainees were equally satisfied with instructional methods (e.g. a presentation) in both training settings. Reviewing meta-analyses, Bell and Federman (2013) found that that e-learning produces training outcomes equivalent to classroom training when instructional conditions are held constant. Nevertheless, meta-analyses have found differences between e-learning and classroom training (Arthur et al. 2003; Sitzmann et al. 2006). Results revealed smaller effect sizes for e-learning within the categories of reactions $(d=0.31)$, behavioural changes $(d=0.32)$, and success of learning $(d=0.40)$ compared with classroom training (Arthur et al. 2003). However, Sitzmann et al. (2006) have demonstrated that the results differ depending on the type of content learned: Web-based and classroom-instructed training did not differ significantly when teaching procedural knowledge. However, web-based instruction was somewhat more effective than classroom instruction when teaching declarative (factual) knowledge, especially in long courses. This superiority effect of web-based training increased by $19 \%$ when (a) trainees were able to control the content and sequence in the learning process, (b) trainees received feedback during training, and (c) trainees had opportunities to practice the training material. Similarly, a more recent meta-analytic review of online training studies from 1996 to 2008 has revealed that students perform modestly better in e-learning settings than do students learning the same content via face-to-face instruction (Means et al. 2010). Pedagogical features (e.g. learner control, practice, and feedback) and conditions influencing training effectiveness have been argued to play a critical role for maximum learning outcomes across studies (Bell et al. 2017); however, it remains unclear how practitioners apply such transfer support actions differently according to the specific training design.

\section{Present study}

Overall, the present study investigates various issues: The main focus is on the sciencepractice gap regarding strategies fostering transfer and thus answers the question to what extent do companies implement strategies in practice, first, for both training settings and second, specifically in e-learning. Third, differences in such strategies between e-learning and classroom training are investigated. Fourth, we scrutinise the transfer problem by comparing the degree of such strategies regarding different time periods.

\section{Implementation of actions for maximising training effectiveness in both training settings}

To optimally use the training content learned, research in the field of Training and Development (T\&D) has identified a variety of actions for maximising training effectiveness 
(Salas et al. 2012). To what extent do companies apply evidence-based actions that are well-investigated in the current $\mathrm{T} \& \mathrm{D}$ research literature in order to maximise training effectiveness? How intensively do companies already support their e-learning and classroom training by implementing actions for maximising training effectiveness before, during, and after training?

$R Q$ 1: To what extent do companies implement actions for maximising training effectiveness that maximise the success of learning and the success of transfer?

\section{Implementation of specific e-learning actions for maximising training effectiveness}

In recent decades, the transfer of information via e-learning has become more and more important, which is indicated by the vast implementation of e-learning settings in the corporate sector (Fry 2001; Kimiloglu, Ozturan, and Kutlu 2017). Companies are even experiencing a shift from traditional classroom training to e-learning. According to the transfer process model (Baldwin and Ford 1988), training design plays a key role in training transfer. Thus, regardless of which training setting is used (e-learning or classroom training), it is important to construct training designs that highly support training transfer. Salas et al. (2012) have identified specific e-learning actions for maximising training effectiveness. Responding to the current shift from traditional classroom training to e-learning, we are faced with the question of the extent to which corporate businesses apply these specific e-learning actions to maximise training effectiveness.

$R Q$ 2: To what extent do companies implement specific e-learning actions for maximising training effectiveness that also maximise the success of learning and the success of transfer?

\section{Implementation of actions for maximising training effectiveness: comparing training settings}

It is necessary to consider the question of whether there were differences in the implementation of actions for maximising training effectiveness between e-learning and classroom training across three time periods. Companies invest in e-learning settings to save costs (Bedwell and Salas 2010). Consequently, professional consulting for e-learning programs is barely sought after. Less than $1 \%$ of the costs invested in e-learning settings were spent on consulting (i.e. for implementation, didactical design, or application in practice) for professional e-learning programs supporting the transfer of learning (MMB 2010). Moreover, companies have a stronger interest in offering innovative and entertaining learning platforms to their employees instead of focusing on their potential regarding the transfer of learning (Bedwell and Salas 2010). Therefore, we propose:

$R Q$ 3: Are fewer actions for maximising training effectiveness implemented in e-learning compared with classroom training settings across all three time periods - before (RQ 3a), during (RQ 3b), and after training (RQ 3c)?

\section{Implementation of actions for maximising training effectiveness: comparing time periods}

The final issue refers to the transfer problem itself, which has been demonstrated in several scientific studies (e.g. Baldwin and Ford 1988; Grossman and Salas 2011; Saks, Salas, and 
Lewis 2014): Fewer actions for maximising training effectiveness are implemented after training courses. For example, support from supervisors and colleagues, positive and negative consequences, phases of exercises, and meaningful and analytical feedback are transfer support actions after training, but they are often insufficiently considered. In corporate practice, only $9 \%$ of companies assessed the success of transfer, and only $7 \%$ assessed organisational results within their evaluations (Van Buren and Erskine 2002). Instead, companies analysed the success of satisfaction at 78\% and the success of learning at 32\% (Van Buren and Erskine 2002). Furthermore, companies tend to focus on aspects during training by presenting factual information and good-looking designs (Salas et al. 2012).

$R Q$ 4: Are actions for maximising training effectiveness implemented least after training compared with before and during training in e-learning and classroom training?

\section{Study context}

The aim of the current study is to investigate the transfer problem in the workplace. As $\mathrm{T} \& \mathrm{D}$ professionals are responsible for actively guiding employees' learning process and maximising the success of learning and the success of transfer (Velada et al. 2007; Hochholdinger and Beinicke 2011), their perspective was investigated. In this study, T\&D professionals were employed at companies from diverse branches of industry and that are among the best and most popular employers in Germany. For a better understanding of the research context, background information is provided next.

The target group participating in corporate e-learning and classroom training comprised clerks, managers, skilled employees, and sales staff. Managers were slightly more likely to be trained in classroom training; otherwise, there were no differences in the choice of training setting regarding each target group.

General information about implementing e-learning, such as period and various forms, revealed that more than two-thirds of the companies surveyed - namely banks and insurance or services - offered e-learning as part of their HRD activities. Only one-third of the companies did not implement e-learning for knowledge transfer in their training (e.g. healthcare and social services). Overall, e-learning had been implemented as part of training settings for a mean of eight years with a high standard deviation and a range from one to 25 years $(M=7.82, S D=4.82)$. More than half $(53.3 \%)$ of the companies - namely banks and insurances as well as services - had been using e-learning for more than six years. These companies had significantly higher numbers of employees and turnover. Only $23.3 \%$ of the companies had been using e-learning for 0-3 years. With regard to each form of e-learning, web-based training (49.5\%), learning platforms (36.1\%), blended learning (27.8\%), and computer-based training (26.8\%) were most commonly used, with only fairly common or very common use of various e-learning forms. Wikis and blogs (20.6\%), podcasts (15.5\%), and virtual classrooms (14.4\%) were comparatively rarely implemented. Business games and simulations have not yet been frequently used in most of the companies.

\section{Materials and methods}

\section{Participants}

To gain a representative insight into the work environment, our sample comprised T\&D professionals from companies that constitute the best and most popular employers in 
Germany. According to objective evaluation criteria, the selection of the sample was based on rankings of best workplaces in Germany awarded by established research and consulting institutes (Top Employers Institute, Great Place to Work Germany, and Trendence Institute). The ranking of the Top Employers Institute comprised the categories Top Employers Germany, Top Employers Engineers Germany, and Top Employers Automotive Germany and included about 170 companies (Top Employers Institute 2013). Objective evaluation criteria included T\&D possibilities, career opportunities, and company culture (Top Employers Institute 2013). Data from Great Place to Work ${ }^{\circledast}$ (2012) included companies of all sizes, industry classifications, and regions that had received awards in the categories Germany's Best Workplaces 2012 and Best Workplaces in Health Services for their special quality of organisational culture (e.g. fairness, credibility), leadership or career development, and attractiveness as a workplace. The ranking of the Trendence Institute (2013) subsumed companies that were rated as the most attractive employers in Germany based on brand recognition value and the companies' attractiveness to young professionals in the categories Business, Engineering, Information Technology, and Law.

\section{Characteristics of companies and T\&D professionals}

Overall, companies from more than 14 different branches of the industry participated in the study. Service industries (14.2\%) as well as healthcare and social services (13.3\%) were most frequently represented, followed by banks and insurance (9.2\%), tax advisory and consulting (8.3\%), industrial engineering and construction $(6.7 \%)$, media and telecommunications (5.8\%), chemicals and pharmaceuticals (5.8\%), automobiles and parts (5.8\%), consumer and industrial goods (5.0\%), and trade (5.0\%), utilities (4.2\%), electronics and electrical engineering (4.2\%), technology (3.3\%), legal consulting (2.5\%), and others (6.7\%). The size of the enterprise was determined by a number of employees and turnover. Based on the recommendation of the European Commission (IfM 2014), companies are defined as small and medium-sized enterprises when less than 250 workers are employed and the turnover per fiscal year does not exceed 50 million euros. The goal of the study was to (a) investigate mainly large-scale companies to make the study results applicable for a large number of employees and (b) focus on a national outreach within each company to generalise the study results across each company. Mostly enterprises participated in the study $(85.0 \%)$, whereas only few companies were small and medium-sized enterprises $(15.0 \%)$.

The questionnaire was completed by T\&D professionals mainly from the headquarters of the companies (91.3\% HR managers, HR representatives, HR employees, HR project managers, or HR assistant managers), CEOs (4.3\%), and others (4.3\%). Participants had six years of training responsibility on average, ranging from less than one year up to 30 years. More than half of these participants $(52.1 \%)$ had been responsible for training for more than three years $(M=5.95, S D=6.17)$.

\section{Procedure}

Cross-sectional data were collected with an online questionnaire between December 2012 and May 2013. Companies were first invited to participate by phone $(n=529)$ and later via email $(n=487)$. Despite being represented in several rankings, each company participated 
only once in the study. The final sample that was considered in the analyses comprised 134 companies; thus, a response rate of $27.5 \%$ was achieved. In compensation, participants received non-monetary incentives, that is, an anonymous benchmark as well as a checklist of evidence-based recommendations and best practices for maximising training effectiveness.

\section{Instrument}

\section{Implementation of actions for maximising training effectiveness}

Items for evaluating actions for maximising training effectiveness were based on the checklist by Salas et al. (2012). This checklist subsumes a wide range of theoretical models as well as evidence-based recommendations and best practices. We used the translation-back-translation technique (e.g. Van de Vijver and Leung 1997) to construct a German version of the questionnaire. Participants rated the occurrence of each action on a 5 -point Likert scale $(1=$ never to $5=$ always $)$. Based on the Salas checklist, items were subsumed into scales.

The questionnaire contained actions for maximising training effectiveness for e-learning only and actions for maximising training effectiveness for both training settings. For specific e-learning actions, the scales refer to adequately design e-learning settings ( $\alpha=.60$, $n=5$, sample item: we ensure that our e-learning actions are based on the sound instructional design) and use simulation appropriately $(\alpha=.91, n=4$, sample item: we ensure that the simulation is job relevant, even if it is not identical to the job). For actions relevant to both training settings across all time periods (before, during, and after training), each item was presented in a parallel structure and had to be answered for both training settings so that a direct comparison was possible.

With regard to actions before training, seven scales (20 items) were included: (1) conduct a job-task analysis (EL: $\alpha=.65$, CT: $\alpha=.48, n=4$ ), (2) conduct a person analysis (EL: $\alpha=.64$, CT: $\alpha=.37, n=4$, sample item: we geared the structure of our training especially to the needs of elderly employees), (3) conduct an organisational analysis (2 items, $n=4$, sample item: we determine if our company guidelines (culture, norms) support the training), (4) schedule training (2 items), (5) notify employees (EL: $\alpha=.76$, CT: $\alpha=.68, n=4$, sample item: we communicate clear expectations about the training), (6) establish attendance policies (2 items), and (7) prepare supervisors and leaders (2 items).

With regard to actions during training, seven scales (19 items) were administered: (1) build self-efficacy (EL: $\alpha=.79$, CT: $\alpha=.64, n=4$, sample item: training is delivered in a way that builds trainees' belief in their ability to learn), (2) promote a learning orientation (1 item), (3) boost motivation to learn (EL: $\alpha=.81$, CT: $\alpha=.82, n=3$ ), (4) use a valid training strategy and design (EL: $\alpha=.72$, CT: $\alpha=.67, n=4)$, (5) build in opportunities for trainees to engage in transfer-appropriate processing (EL: $\alpha=.68$, CT: $\alpha=.58, n=3$ ), (6) promote selfregulation (2 items, sample item: we keep participants on task by encouraging their selfmonitoring), and (7) incorporate errors into training (2 items).

Actions after training were assessed by six scales (22 items): (1) remove obstacles to transfer (2 items), (2) provide tools and advice for supervisors (2 items), (3) encourage use of real-world debriefs (EL: $\alpha=.85$, CT: $\alpha=.73, n=6$, sample item: after training, we reinforce lessons learned [e.g. praise by supervisors]), (4) provide other reinforcement and support mechanisms (EL: $\alpha=.64$, CT: $\alpha=.46, n=3$ ), (5) clearly specify the purpose 
of evaluation (2 items), and (6) consider evaluating training at multiple levels (EL: $\alpha=.84$, CT: $\alpha=.79, n=7$, sample item: we evaluate results at the company level [e.g. increase in productivity]).

\section{Results}

\section{Implementation of actions for maximising training effectiveness in both training settings}

RQ 1, to what extent do companies implement actions for maximising training effectiveness that maximise the success of learning and success of transfer, is answered by presenting descriptive results separately for before, during, and after training $(M, S D$; see Table 1$)$.

\section{Before training}

Descriptive analyses revealed high means for both forms of learning, all $M s \geq 3.33$. Thus, actions for maximising training effectiveness were sometimes to almost always implemented before training. Notably, actions in e-learning displayed higher standard deviations and more missing data than in classroom training. In particular, companies almost always notify employees, establish attendance policies, prepare supervisors and leaders, conduct an organisational analysis, conduct a person analysis, and schedule training in both training settings. A job-task analysis was only sometimes conducted, showing the lowest means in both training settings. Although high means in both training settings were obtained, there is room for potential improvement.

Examining single items more closely, the results revealed a demand for adapting the training environment to meet the needs of older workers (EL: $M=2.09, S D=1.13$; CT: $M=2.30, S D=1.04)$. In addition, conducting a cognitive task analysis for knowledgebased jobs was almost never considered (EL: $M=1.67, S D=0.93$; CT: $M=1.73, S D=$ 0.97 ). The mandatory label was sometimes used selectively (EL: $M=3.28, S D=1.49$; CT: $M=3.20, S D=1.54$ ), thereby leaving room for voluntary attendance that helps to ensure the learner's motivation and course attendance and that helps to maximise the success of transfer (for meta-analytical details, see Blume et al. 2010). The companies only sometimes examined teamwork demands, if needed, especially in e-learning settings (EL: $M=2.93, S D=1.38$ ). Since the single item regarding the selection and competence of trainers was phrased rather specifically for classroom training, no further comparative analysis was conducted.

\section{During training}

Similar to the effects found before training, the results showed (a) high means for e-learning and classroom trainings, (b) higher standard deviations in e-learning, and (c) more missing data in e-learning. Compared with the results before training, we found even higher means in both training settings (EL: $M_{\min -\max }=3.4-4.1$, sometimes to almost always; CT: $M_{\min -\max }=3.8-4.5$, almost always to always). Generally during training, companies almost always put a lot of effort into almost all transfer support actions. In particular, they almost always promote learning orientation and boost motivation to learn, with the highest values obtained in both training settings. The lowest value was achieved for incorporating errors into training in both training settings (sometimes to almost always). 
Table 1. Implementation of actions for maximising training effectiveness comparing training settings.

\begin{tabular}{|c|c|c|c|c|c|c|c|}
\hline \multirow[b]{2}{*}{ Time period } & \multirow[b]{2}{*}{$n$} & \multicolumn{4}{|c|}{$\begin{array}{l}\text { Classroom } \\
\text { training }\end{array}$} & \multirow[b]{2}{*}{$p$} & \multirow[b]{2}{*}{$d$} \\
\hline & & $M$ & $S D$ & $M$ & $S D$ & & \\
\hline Before training & 81 & 3.60 & 0.73 & 3.92 & 0.52 & .000 & 0.505 \\
\hline Conduct a job-task analysis & 93 & 3.33 & 0.94 & 3.55 & 0.78 & .000 & 0.255 \\
\hline Conduct a person analysis & 93 & 3.51 & 0.79 & 3.84 & 0.60 & .000 & 0.470 \\
\hline Conduct an organisational analysis & 90 & 3.67 & 1.23 & 3.92 & 0.95 & .000 & 0.227 \\
\hline Schedule training & 92 & 3.54 & 0.91 & 3.61 & 0.71 & .452 & 0.086 \\
\hline Notify employees & 93 & 3.99 & 0.80 & 4.17 & 0.59 & .000 & 0.256 \\
\hline Establish attendance policies & 89 & 3.91 & 1.12 & 3.88 & 1.15 & .115 & -0.026 \\
\hline Prepare supervisors and leaders & 88 & 3.63 & 1.20 & 4.02 & 0.89 & .000 & 0.369 \\
\hline During training & 81 & 3.74 & 0.58 & 4.07 & 0.43 & .000 & 0.646 \\
\hline Build self-efficacy & 82 & 3.77 & 0.72 & 4.07 & 0.54 & .000 & 0.471 \\
\hline Promote learning orientation & 80 & 4.13 & 0.91 & 4.46 & 0.69 & .003 & 0.409 \\
\hline Boost motivation to learn & 83 & 4.03 & 0.67 & 4.38 & 0.52 & .000 & 0.584 \\
\hline Use valid training strategy and design & 84 & 3.66 & 0.74 & 3.96 & 0.64 & .001 & 0.434 \\
\hline $\begin{array}{l}\text { Build in opportunities for trainees to engage in transfer-appropriate } \\
\text { processing }\end{array}$ & 79 & 3.96 & 0.72 & 3.86 & 0.58 & .001 & -0.153 \\
\hline Promote self-regulation & 74 & 3.68 & 0.71 & 3.97 & 0.64 & .000 & 0.429 \\
\hline Incorporate errors into training & 68 & 3.36 & 0.91 & 3.75 & 0.83 & .000 & 0.448 \\
\hline After training & 81 & 3.16 & 0.78 & 3.40 & 0.63 & .000 & 0.339 \\
\hline Remove obstacles to transfer & 73 & 3.35 & 0.92 & 3.52 & 0.86 & .008 & 0.191 \\
\hline Provide tools and advice to supervisors & 75 & 3.38 & 0.89 & 3.67 & 0.80 & .000 & 0.343 \\
\hline Encourage use of real-world debriefs & 78 & 2.93 & 0.83 & 3.34 & 0.70 & .000 & 0.534 \\
\hline Provide other reinforcement and support mechanisms & 81 & 3.10 & 0.90 & 3.20 & 0.83 & .038 & 0.116 \\
\hline Clearly specify purpose of evaluation & 77 & 3.57 & 1.08 & 3.99 & 0.92 & .000 & 0.419 \\
\hline Consider evaluating training at multiple levels & 81 & 3.11 & 0.97 & 3.26 & 0.84 & .011 & 0.165 \\
\hline
\end{tabular}

Looking closely at single items in both training settings, we noticed that trainees were only sometimes encouraged to make mistakes during training ( $\mathrm{EL}: M=2.90, S D=1.10$; CT: $M=3.39, S D=0.92)$ and that demonstrations of bad behaviour were too rarely provided (EL: $M=3.30, S D=1.21$; CT: $M=3.58, S D=1.04$ ). In addition, a relatively low value was obtained for giving meaningful and diagnostic feedback to trainees, especially in elearning (EL: $M=3.19, S D=1.06$; CT: $M=3.78, S D=0.82$ ).

\section{After training}

In both training settings, means of actions for maximising training effectiveness after training were lower than before and during training. Again, data in e-learning settings varied more in terms of standard deviation and missing data. The scale clearly specifying the purpose of evaluation scored highest in both training settings. Thus, the companies almost always determined what they hope to accomplish by evaluating training, and they linked all subsequent decisions back to their purpose. After training, companies almost always provide tools and advice to supervisors, but only in classroom training, whereas in e-learning, all other actions are only sometimes implemented. The scales providing other reinforcement and support mechanisms and considering evaluating training at multiple levels were relatively low in value compared with others (only sometimes implemented), thus indicating the tremendous potential for improvement.

Analyses at the single-item level revealed that virtual or real 'communities of practice' were almost never used to reinforce and support the content that trainees learned during 
training (EL: $M=2.39, S D=1.13$; CT: $M=2.49, S D=1.05$ ). Moreover, implementing a plan of action (agreements) between the trainee and supervisor was relatively rare (EL: $M=2.46, S D=1.11$; CT: $M=2.79, S D=1.04)$.

In terms of considering evaluating training at multiple levels, we found that all companies obtained quite high values when measuring participants' satisfaction with training and their success of learning (see Figure Supplemental 1). However, all other levels dealing with the measurement of success of transfer, training success at the company level, and the use of precise affective, cognitive, and/or behavioural indicators to measure the intended learning outcomes were disregarded (almost never to sometimes), which illustrates a potential for improvement.

Overall, to answer RQ 1, companies almost always implement actions for maximising training effectiveness before and during training in both training settings (besides two scales in e-learning). However, after training, transfer-supportive actions are rather only sometimes implemented. Generally, more variance was found in e-learning than in classroom training indicating greater differences in considering transfer-supportive actions in e-learning across companies.

\section{Implementation of specific e-learning actions for maximising training effectiveness}

RQ 2, to what extent do companies implement specific e-learning actions for maximising training effectiveness that also maximise the success of learning and the success of transfer, is answered by presenting descriptive results $(M, S D$; see Table 2).

The majority of companies almost always designed their e-learning settings adequately $(M=4.06, S D=0.60)$. To be more specific, data at the single-item level revealed that the companies almost always ensure that their e-learning actions are based on sound instructional design $(M=4.27, S D=0.81)$ and that they carefully consider which training topics can be delivered via e-learning $(M=4.25, S D=0.90)$. Furthermore, in case of questions and problems, participants get support from a hotline or an IT department, and trainees are provided with feedback and are offered sufficient structure and guidance to allow them to make decisions about their learning experience. To answer RQ 2 regarding the extent to which companies implement specific e-learning actions that maximise the success of learning and the success of transfer, we conclude that the companies were good at maximising the success of transfer, as indicated by their high values in designing their e-learning settings adequately even though there is still some room for improvement.

However, regarding the scale that measures the appropriate use of simulations, a relatively low value with high standard deviation and a great deal of missing data was obtained $(M=2.62, S D=1.18)$. Here, the companies showed low values (almost never) in using simulations to train complex and dynamic skills $(M=2.32, S D=1.10)$ and in guiding practice $(M=2.47, S D=1.10)$.

\section{Implementation of actions for maximising training effectiveness: comparing training settings}

\section{Before training}

$T$-tests showed significant mean differences in favour of classroom training in almost all scales, all ps $\leq .01$ : conduct a job-task analysis, conduct a person analysis, conduct an 
Table 2. Implementation of specific e-learning actions for maximising training effectiveness.

\begin{tabular}{|c|c|c|c|}
\hline & $n$ & M & $S D$ \\
\hline Adequately design e-learning settings & 97 & 4.06 & 0.60 \\
\hline We ensure that our e-learning actions are based on sound instructional design. & 89 & 4.27 & 0.81 \\
\hline We consider carefully which training topics can be delivered via e-learning. & 93 & 4.25 & 0.90 \\
\hline In case of questions and problems, participants get support from a hotline or an IT department. & 96 & 4.16 & 1.03 \\
\hline When implementing e-learning, trainees are provided with feedback. & 90 & 3.82 & 1.07 \\
\hline $\begin{array}{l}\text { Participants are offered sufficient structure and guidance to allow them to make decisions about their } \\
\text { learning experience. }\end{array}$ & 87 & 3.83 & 0.87 \\
\hline Use simulation appropriately & 73 & 2.62 & 1.18 \\
\hline We ensure that simulation is job relevant, even if it is not identical to the job. & 66 & 3.23 & 1.58 \\
\hline When implementing simulations, the opportunity for performance diagnosis and feedback is built in. & 62 & 2.71 & 1.40 \\
\hline After implementing simulations, practice is guided. & 56 & 2.47 & 1.10 \\
\hline Simulations are used to train complex and dynamic skills (particularly those that may be dangerous). & 59 & 2.32 & 1.10 \\
\hline
\end{tabular}

Note: Mean on Likert scale ranging from 1 (never) to 5 (always).

organisational analysis, notify employees, and prepare supervisors and leaders (see Table 1 and Figure Supplemental 2). No significant differences between training settings occurred for schedule training or establish attendance policies. In summary, the results confirmed RQ $3 \mathrm{a}$ as fewer actions for maximising training effectiveness before training are implemented in e-learning compared with classroom training settings.

\section{During training}

Results during training revealed the same underlying structure as before training (see Table 1 and Figure Supplemental 3). That is, actions to maximise training effectiveness were significantly more often implemented in classroom training than in e-learning settings (all ps $<.01$ ), confirming RQ $3 \mathrm{~b}$.

\section{After training}

As displayed in Table 1 and Figure Supplemental 4, results indicated significant mean differences of actions for maximising training effectiveness after training in favour of classroom training in all scales (all $p s<.05$ ), confirming RQ $3 c$. Significant differences $(p<.05)$ indicating a small effect between both training settings were found for providing other reinforcement and support mechanisms and for considering evaluating training at multiple levels.

\section{Implementation of actions for maximising training effectiveness: comparing time periods}

An analysis of variance with two within-subjects factors was conducted to assess the impact of the two different training settings (e-learning, classroom training) on participants' scores on a 5-point Likert scale measuring the implementation of actions for maximising training effectiveness across all scales within the three time periods of training (before, during, and after training). The overall substantial main effect (across all scales for each time period separately) when comparing the two training settings was significant, Wilks' Lambda $=.58, F(1,80)=57.26, p<.001, \eta_{\text {partial }}^{2}=.42$, suggesting a difference in the implementation of actions for maximising training effectiveness between the two training settings. Furthermore, there was a substantial main effect for the time period, Wilks' Lambda $=.38, F(1,80)=63.72, p<.001, \eta_{\text {partial }}^{2}=.62$, with both training settings 


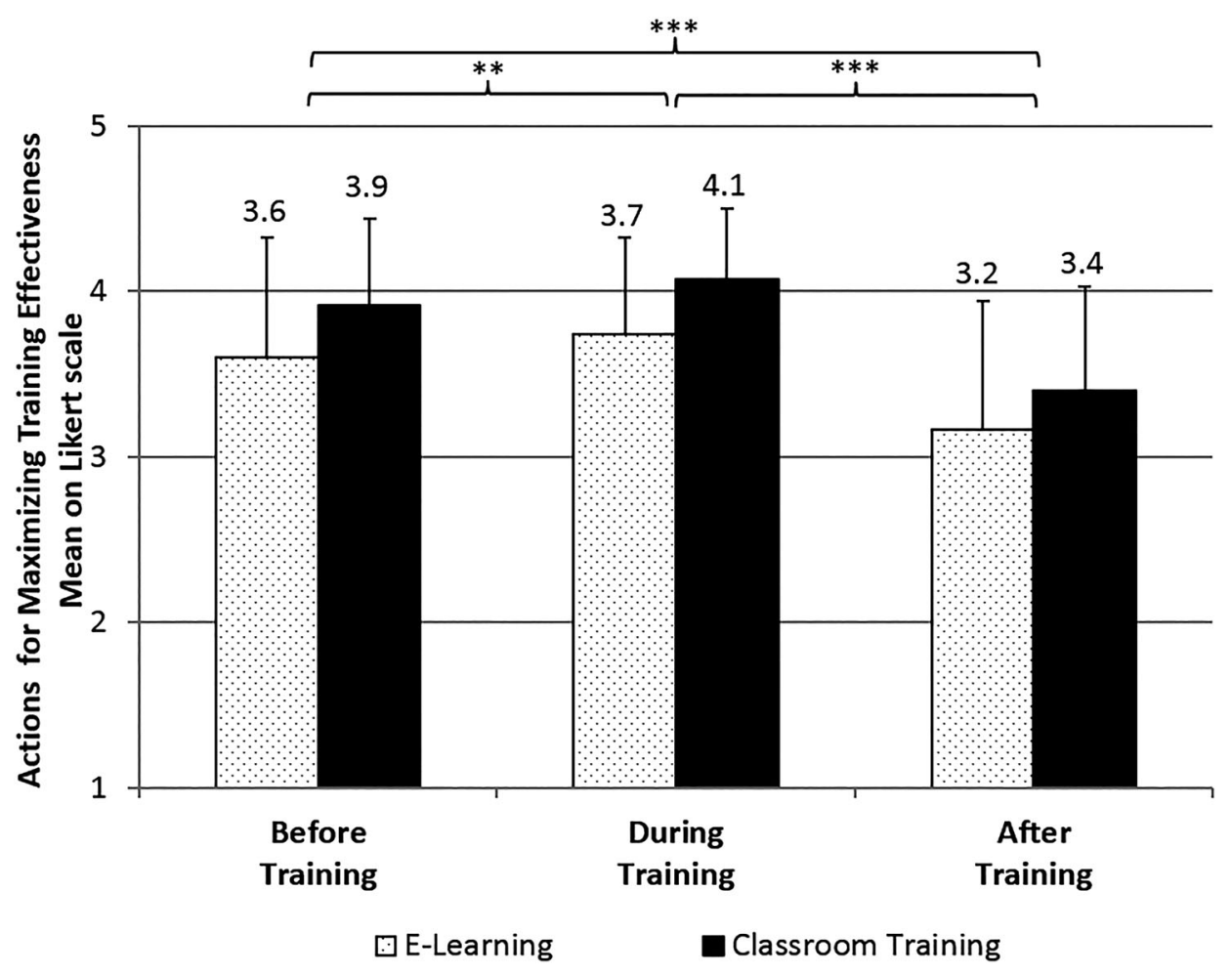

Figure 1. Comparisons of means of the implementation of actions for maximising training effectiveness before, during, and after training in e-learning and classroom training. $n=81$. Tests of within-subjects contrasts showed very large effects for before and after training $\left(^{* * *} p<.001\right)$ as well as for during and after training $\left({ }^{* *} p<.001\right)$ but only a medium effect for before and during training $\left({ }^{* *} p<.01\right)$.

showing an overall reduction in scores pertaining to the implementation of actions for maximising training effectiveness across time periods (see Figure 1). There was no significant interaction between training settings and time periods, Wilks' Lambda $=.95, F(1,80)$ $=2.11, p=.13, \eta_{\text {partial }}^{2}=.050$. Tests of within-subjects contrasts showed a very large effect for differences between before and after training $\left(p<.001, \eta_{\text {partial }}^{2}=.47\right)$ as well as between during and after training $\left(p<.001, \eta_{\text {partial }}^{2}=.61\right)$, always with lower scores for the time period after training. The difference between before and during training revealed a much smaller effect $\left(p<.01, \eta_{\text {partial }}^{2}=.090\right)$. Thus, RQ 4 was confirmed since actions for maximising training effectiveness are least implemented after training compared with before and during training in both training settings.

\section{Discussion}

\section{Summary and practical implications}

The present study aimed at contributing to the science-practice gap regarding the application of evidence-based actions for maximising training effectiveness in corporate practice. In the following section, key findings are summarised together with their corresponding implications for practice. 
First, regarding the RQ to what extent transfer-supportive actions are implemented before, during, and after training in companies that have been awarded 'best employers in Germany', high means were generally found in both training settings, especially before and during training, with higher standard deviations in e-learning than in classroom training. Before training, besides conducting a job-task analysis in e-learning only sometimes, companies almost always consider all transfer-supportive actions. During training, companies put great effort into almost all transfer support actions (and especially into promoting learning orientation and boosting motivation to learn). After training, companies clearly specify the purpose of evaluation as well as provide tools and advice to supervisors, but only in classroom training; in e-learning, on the other hand, all actions are only sometimes implemented.

Focusing on actions that were almost never or only sometimes implemented in practice, the following issues and practical implications have to be considered. Before training, adapting the training environment to meet the needs of older workers was rarely implemented. This finding calls for a demand to ensure a fit with trainees' needs, particularly in terms of an aging workforce. With regard to actions during training, incorporating errors into training is rarely considered in practice. As prior research has revealed that integrating error management during training correlates with the success of the transfer (Keith and Frese 2008; Watson et al. 2013), equipping trainees to deal with situations containing errors on the job and monitoring their behaviour during training is highly recommended. After training, encouraging the use of real-world debriefs is not often applied in practice; therefore, it seems necessary to foster this practice in the future (Salas et al. 2012). Consequently, this action promotes adequate mental models, content retention, self-efficacy, and motivation and thus also improves job performance (SmithJentsch et al. 2008; Salas et al. 2012). We have identified the potential for improvement in providing other reinforcement and support mechanisms. Therefore, companies should, for example, provide job aid or access to knowledge repositories or communities of practice to improve job performance (e.g. Gallupe 2001; Wenger, McDermott, and Snyder 2002; Salas et al. 2012). Furthermore, almost all items of the scale considering evaluating training at multiple levels were only almost never to sometimes implemented after training. Our results thus confirm the lack of systematic evaluation after training, which has been consistently found in other studies (e.g. Patel 2010). As the importance of monitoring the learning process for the success of learning and the success of transfer has been widely demonstrated (e.g. Saks and Burke 2012), we emphasise that more systematic, multilevel evaluation is needed in corporate practice in the future. Adequately evaluating training allows for well-grounded decisions about the training - including any necessary modifications - and for maintaining the training's effectiveness (Salas et al. 2012).

In summary, even though high means in both training settings were obtained (primarily before and during training), there is room for potential improvement, especially in meeting the needs of older workers, integrating error management, encouraging the use of real-world debriefs, providing reinforcement and support mechanisms, and evaluating training at multiple levels.

Second, to answer our RQ regarding the extent to which companies implement specific e-learning actions for maximising training effectiveness, we conclude that companies are good at designing their e-learning settings adequately, as indicated by high values, for example, in terms of carefully considering which training topics can be delivered via e- 
learning. Nevertheless, there is still room for improvement, especially in providing feedback, structure, and guidance to enable trainees to engage in self-regulatory processes and to reflect and adjust their self-paced learning processes (Gravill and Compeau 2008). Feedback loops help trainees to further monitor their progress towards goals and thereby enhance learning (Kluger and DeNisi 1996; Cannon and Witherspoon 2005; Hattie and Timperley 2007; Salas et al. 2012). Contrary to the high values previously examined, the companies displayed low values (almost never) with a great deal of missing data in using simulations appropriately, for example, in training complex and dynamic skills. Missing data can be explained: Only $10.3 \%$ of companies fairly commonly or very commonly used simulations. It is possible that the companies rarely deal with situations in which simulations are the first choice in training setting, for example, for situations that involve particularly dangerous actions. Well-designed simulations enhance learning, improve performance, and help minimise errors, yet this potential of simulations may well remain untapped (Salas et al. 2012).

Third, regarding the main research focus on comparing training settings, results confirm that fewer actions for maximising training effectiveness are implemented in elearning compared with classroom training settings across all three time periods (before, during, and after training). Even though high standard deviations occurred (especially in e-learning settings), on average, there were significant differences between both training settings for most of the scales. One reason for this outcome could be that e-learning is constructed and implemented too fast or that not enough expertise is present to incorporate the variety of well-investigated evidence-based actions for maximising training effectiveness known from the current T\&D research literature (Salas et al. 2012). Another reason could be that the costs for e-learning settings (especially software) are much higher compared with classroom training settings, especially when they are additionally implemented (Bedwell and Salas 2010; MMB 2010).

Fourth, comparing time periods, our results confirm that actions for maximising training effectiveness are least implemented after training compared with before and during training in e-learning and classroom training. These findings are in line with previous findings regarding the transfer problem (e.g. Baldwin and Ford 1988; Grossman and Salas 2011; Saks, Salas, and Lewis 2014). More specifically, on the one hand, our results affirm Van Buren and Erskine's (2002) findings that companies investigate transfer support actions before and during training instead of after training. On the other hand, our results affirm findings by Salas et al. (2012) that companies tend to focus on aspects during training, as indicated by the highest means of actions for maximising training effectiveness. However, the aspects after training are most relevant to maximising training success on a long-term basis, for example, support from supervisors and colleagues, positive and negative consequences, phases of exercises, or meaningful and analytical feedback (Hattie and Timperley 2007; Salas et al. 2012).

From an applied HRD perspective, the increasing digitalisation also in the field of T\&D requires an even stronger focus of promoting transfer-supportive actions in e-learning. Throughout the training process (before, during, and especially after training), companies should more consistently apply strategies that matters for maximising training effectiveness, so that training is sustainable and its investments pay off in the long run.

Due to the selected sample (i.e. large-scale enterprises with high numbers of turnover and employees from various branches of industry, awarded as 'best employers in 
Germany'), the results should be interpreted mainly nationally and partially internationally. The companies reported that their responses to the implementation of actions for maximising training effectiveness have a national and even an international scope of application $(74.3 \%)$. This accounts for the high practical impact for both trainees and T\&D professionals and also demonstrates the relevance of this exploratory study for research in the field of T\&D.

\section{Contribution to HRD theory}

From a theoretical perspective, the present study contributes to the HRD theory by building on the framework of Salas et al. (2012). The comparison of both training settings corporate e-learning and classroom training - across three time periods serves as a refinement of the model by Salas et al. (2012). As fewer actions for maximising training effectiveness are implemented in e-learning, this study demonstrates that companies in practice lag behind necessary adjustments when implementing e-learning.

Taking transfer-supportive actions in e-learning into greater account becomes especially important in times of digital change when the transfer of information via elearning settings has increased and partially compensated traditional classroom training. According to Baldwin and Ford's (1988) transfer process model and along the discussion on which training setting is more effective given certain circumstances (e.g. Sitzmann et al. 2006), this study supports the decisive role of the training design by additionally focussing on specific e-learning actions for maximising training effectiveness.

\section{Limitations and suggestions for future research}

A first limitation is the sole usage of evidence-based actions for maximising training effectiveness, as presented by Salas et al. (2012). As a consequence, all strategies and actions that have been identified in prior research may not have been included in this study. For example, the following questions remain open: (a) What specific features of new technologies (e.g. social media) actually contribute to learning? (b) How and why do specific types of training result in learning? (c) What higher-order skills do experts use to execute a task? and (d) What is the contribution of blended or informal learning? Even though the checklist presented by Salas et al. (2012) subsumes a whole body of evidence-based research findings on training effectiveness relevant for practice, its mere application cannot be interpreted as deterministic, leading to training success. Despite relative simplicity of the checklist, it helps in bridging the science-practice gap.

A second limitation of this study refers to the generalisability of results: Altogether, we selected companies for our study that had received awards in excellence regarding HRD activities; thus, we may tend to overrate the effects compared to other companies that do not do as quite as much as the companies investigated. Also, inflated responses can also be due to respondents' assumption that high scores are preferable. In addition, data from the companies were based on the person most responsible for the company's HRD activities, who was asked to fill in the questionnaire. However, there is no proof that this person always represented the head of the T\&D department. To confirm our results and make them more influential, more companies with a national or even international scope of application and multidimensional assessments need to be investigated, 
for example, by also including trainees, colleagues of trainees, or supervisors in addition to T\&D professionals. However, investigating this special-selected sample, we fulfil the hope that the results nowadays are even more relevant educationally and economically as Great Place to Work ${ }^{\circledast}$ become even more international with locations in 52 countries worldwide.

We used an online questionnaire to benefit from online assessment advantages (i.e. cost savings and the absence of limitations in time and space). However, the online questionnaire provided no possibility to clarify the meaning of items - even though samples were given for some but not all items that might be awkwardly phrased, vague, or unclear. This may have led to fewer conscientious answers or missing values, especially for the evaluation scale after training. Generally, we assume a tendency to avoid extreme answers and a tendency to answer in a socially desirable manner as these tendencies demonstrate a positive self-signalling of the companies and thereby imply self-presentation.

For future research, it would be interesting to follow-up on this study in order to investigate how companies react to the benchmark as well as to the checklist of evidence-based recommendations and best practices for maximising training effectiveness in order to see whether this reaction has stimulated them to implement these actions (even more often). Including e-learning as such despite many calls for transfer-supportive actions, in reality not that much has changed. As stated by Bell et al. (2017), the examination of learning and transfer that occurs outside the classroom, i.e. in e-learning, is a critical trend and advance in recent decades that needs more attention.

\section{Disclosure statement}

No potential conflict of interest was reported by the authors.

\section{ORCID}

Andrea Beinicke (D) http://orcid.org/0000-0002-2235-7508

Eva Kyndt (D) http://orcid.org/0000-0002-6755-4409

\section{References}

Arthur, W., W. Bennett, P. S. Edens, and S. T. Bell. 2003. "Effectiveness of Training in Organizations: A Meta-analysis of Design and Evaluation Features." Journal of Applied Psychology 88: 234-245. doi:10.1037/0021-9010.88.2.234.

Arthur, W., W. Bennett, P. L. Stanush, and T. L. McNelly. 1998. "Factors that Influence Skill Decay and Retention: A Quantitative Review and Analysis." Human Performance 11: 57-101. doi:10. 1207/s15327043hup1101_3.

ATD Research. 2017. 2017 State of the Industry. Accessed December 30, 2018. https://www.td.org/ research-reports/2017-state-of-the-industry.

Baldwin, T. T., and J. K. Ford. 1988. "Transfer of Training: A Review and Directions for Future Research.” Personnel Psychology 41: 63-105. doi:10.1111/j.1744-6570.1988.tb00632.x.

Baldwin, T. T., J. K. Ford, and B. D. Blume. 2017. "The State of Transfer of Training Research: Moving Toward More Consumer-centric Inquiry." Human Resource Development Quarterly 28: 17-28. doi:10.1002/hrdq.21278.

Bedwell, W. L., and E. Salas. 2010. "Computer-based Training: Capitalizing on Lessons Learned." International Journal of Training and Development 14: 239-249. doi:10.1111/j.1468-2419.2010. 00355.x. 
Bell, B. S., and J. E. Federman. 2013. "E-learning in Postsecondary Education." The Future of Children 23: 165-185. doi:10.1353/foc.2013.0007.

Bell, B. S., S. I. Tannenbaum, J. K. Ford, R. A. Noe, and K. Kraiger. 2017. “100 Years of Training and Development Research: What We Know and Where We Should Go." Journal of Applied Psychology 102: 305-323. doi:10.1037/apl0000142.

Blume, B. D., J. K. Ford, T. T. Baldwin, and J. L. Huang. 2010. “Transfer of Training: A Metaanalytical Review.” Journal of Management 36: 1065-1105. doi:10.1177/0149206309352880.

Cannon, M. D., and R. Witherspoon. 2005. "Actionable Feedback: Unlocking the Power of Learning and Development." Academy of Management Executive 19: 120-134. doi:10.5465/ame.2005.16965107.

Cavanaugh, C. S. 2001. "The Effectiveness of Interactive Distance Education Technologies in K-12 Learning: A Meta-analysis." International Journal of Educational Telecommunications 7: 73-88.

Driskell, J. E., R. P. Willis, and C. Copper. 1992. "Effect of Overlearning on Retention." Journal of Applied Psychology 77: 615-622. doi:10.1037/0021-9010.77.5.615.

Eurostat. 2010. The 4th Continuing Vocational Training Survey (CVTS4): European Union Manual. Luxembourg: European Commission. http://ec.europa.eu/eurostat/statistics-explained/index. php/File:Costs_of_CVT_courses_relative_to_total_labour_costs_for_all_enterprises,_2010,_\% 25_new.png/.

Ford, J. K., T. Baldwin, and J. Prasad. 2018. "Transfer of Training: The Known and the Unknown.” Annual Review of Organizational Psychology and Organizational Behavior 5: 201-225. doi:10. 1146/annurev-orgpsych-032117-104443.

Fry, K. 2001. "E-learning Markets and Providers: Some Issues and Prospects." Education and Training 43: 233-239. doi:10.1108/EUM0000000005484.

Gallupe, B. 2001. "Knowledge Management Systems: Surveying the Landscape." International Journal of Management Reviews 3: 61-77. doi:10.1111/1468-2370.00054.

Govaerts, N., and F. Dochy. 2014. "Disentangling the Role of the Supervisor in Transfer of Training.” Educational Research Review 12: 77-93. doi:10.1016/j.edurev.2014.05.002.

Govaerts, N., E. Kyndt, S. Vreye, and F. Dochy. 2017. "A Supervisors' Perspective on Their Role in Transfer of Training." Human Resource Development 28: 515-525. doi:10.1002/hrdq.21286.

Gravill, J., and D. Compeau. 2008. "Self-regulated Learning Strategies and Software Training." Information and Management 45: 288-296. doi:10.1016/j.im.2008.03.001.

Great Place to Work Institut Deutschland. 2012. Deutschlands beste Arbeitgeber 2012 ausgezeichnet [Germany's Best Employers in 2012]. Accessed March 9, 2018. http://www.presseportal.de/pm/ 69829/2213029/.

Grossman, R., and E. Salas. 2011. “The Transfer of Training: What Really Matters.” International Journal of Training and Development 15: 103-120. doi:10.1111/j.1468-2419.2011.00373.x.

Hammond, D. 2001. "Reality Bytes." People Management 7: 26-31.

Hattie, J., and H. Timperley. 2007. "The Power of Feedback." Review of Educational Research 77: 81-112. doi:10.3102/003465430298487.

Hochholdinger, S., and A. Beinicke. 2011. "Evaluation Betrieblichen E-learnings: Methoden und Befunde [Evaluation of Corporate E-learning: Methods and Findings].” In Handbuch E-learning, edited by A. Hohenstein and K. Wilbers, 6-18. Köln: Deutscher Wirtschaftsdienst.

Hochholdinger, S., and A. Beinicke. 2012. "Potenziale und Herausforderungen Netzbasierten Lernens [Potentials and Challenges of Web-based Learning].” Personal Quarterly 64: 16-23.

Hurtz, G. M., and K. J. Williams. 2009. "Attitudinal and Motivational Antecedents of Participation in Voluntary Employee Development Activities.” Journal of Applied Psychology 94: 635-653. doi:10.1037/a0014580.

IfM (Institut für Mittelstandsforschung Bonn). 2014. KMU-definition der Europäischen Kommission [Definition of SME Enterprises of the European Commission]. Accessed March 9, 2018. https://www.ifm-bonn.org/definitionen/kmu-definition-der-eu-kommission/.

Keith, N., and M. Frese. 2008. "Effectiveness of Error Management Training: A Meta-analysis." Journal of Applied Psychology 93: 59-69. doi:10.1037/0021-9010.93.1.59.

Kimiloglu, H., M. Ozturan, and B. Kutlu. 2017. "Perceptions About and Attitude Toward the Usage of E-learning in Corporate Training." Computers in Human Behavior 72: 339-349. doi:10.1016/j. chb.2017.02.062. 
Kluger, A. N., and A. DeNisi. 1996. "The Effects of Feedback Interventions on Performance: A Historical Review, a Meta-analysis, and a Preliminary Feedback Intervention Theory.” Psychological Bulletin 119: 254-284. doi:10.1037/0033-2909.119.2.254.

Kodwani, A. D. 2017. "Decoding Training Effectiveness: The Role of Organisational Factors." Journal of Workplace Learning 29: 200-216. doi:10.1108/JWL-05-2016-0038.

Kodwani, A. D., and M. Singh. 2004. "Towards Effective Training and Development in Indian Public Sector Enterprises: A Case-based Analysis.” South Asian Journal of Management 11: $36-56$.

Kyndt, E., and H. Baert. 2013. “Antecedents of Employees' Involvement in Work-related Learning: A Systematic Review.” Review of Educational Research 83: 273-313. doi:10.3102/ 0034654313478021.

Machtmes, K., and J. W. Asher. 2000. "A Meta-Analysis of the Effectiveness of Telecourses in Distance Education.” American Journal of Distance Education 14: 27-46. doi:10.1080/ 08923640009527043.

Massenberg, A. C., E. M. Schulte, and S. Kauffeld. 2017. "Never Too Early: Learning Transfer System Factors Affecting Motivation to Transfer Before and After Training Programs." Human Resource Development Quarterly 28: 55-85. doi:10.1002/hrdq.21256.

Means, B., Y. Toyama, R. F. Murphy, M. Baki, and K. Jones. 2010. Evaluation of Evidence-Based Practices in Online Learning: A Meta-analysis and Review of Online Learning Studies. Washington, DC: Department of Education, Office of Planning, Evaluation, and Policy Development.

MMB (Institut für Medien- und Kompetenzforschung). 2010. Telefonische Befragung zum Einsatz von eLearning in deutschen Großunternehmen [Telephone Survey on the Implementation of Elearning in Large German Companies]. http://www.mmb-institut.de/projekte/digitales-lernen/ Einsatz-von-E-Learning-in-deutschen-Grossunternehmen.pdf/.

Patel, L. 2010. ASTD State of the Industry Report 2010. Alexandria: American Society for Training and Development Press.

Podsakoff, P. M., S. B. MacKenzie, J. Lee, and N. P. Podsakoff. 2003. "Common Method Biases in Behavioral Research: A Critical Review of the Literature and Recommended Remedies." Journal of Applied Psychology 88: 879-903. doi:10.1037/0021-9010.88.5.879.

Saks, A. M. 2002. "So What Is a Good Transfer of Training Estimate? A Reply to Fitzpatrick." The Industrial-Organizational Psychologist 39: 29-30. doi:10.1037/e576922011-004.

Saks, A. M., and L. A. Burke. 2012. "An Investigation Into the Relationship Between Training Evaluation and the Transfer of Training." International Journal of Training and Development 16: 118-127. doi:10.1111/j.1468-2419.2011.00397.x.

Saks, A. M., E. Salas, and P. Lewis. 2014. “The Transfer of Training." International Journal of Training and Development 18: 81-83. doi:10.1111/ijtd.12032.

Salas, E., and J. A. Cannon-Bowers. 2001. “The Science of Training: A Decade of Progress.” Annual Review of Psychology 52: 471-499. doi:10.1146/annurev.psych.52.1.471.

Salas, E., S. I. Tannenbaum, K. Kraiger, and K. A. Smith-Jentsch. 2012. "The Science of Training and Development in Organizations: What Matters in Practice." Psychological Science in the Public Interest 13: 74-101. doi:10.1177/1529100612436661.

Sitzmann, T., K. Kraiger, D. Stewart, and R. A. Wisher. 2006. “The Comparative Effectiveness of Web-based and Classroom Instruction: A Meta-analysis.” Personnel Psychology 59: 623-664. doi:10.1111/j.1744-6570.2006.00049.x.

Smith-Jentsch, K. A., J. A. Cannon-Bowers, S. I. Tannenbaum, and E. Salas. 2008. "Guided Team Self-correction: Impacts on Team Mental Models, Processes, and Effectiveness." Journal of Small Group Research 39: 303-327. doi:10.1177/1046496408317794.

Top Employers Institute. 2013. http://www.top-employers.com/.

Trendence Institute. 2013. https://www.deutschlands100.de/deutschlands-100.html/.

Van Buren, M. E., and W. Erskine. 2002. The 2002 ASTD State of the Industry Report. Alexandria: American Society of Training and Development Press.

Van de Vijver, F. R., and K. Leung. 1997. Methods and Data Analysis for Cross-cultural Research. Thousand Oaks, CA: Sage. 
Velada, R., A. Caetano, J. W. Michel, B. D. Lyons, and M. J. Kavanagh. 2007. "The Effects of Training Design, Individual Characteristics and Work Environment on Transfer of Training." International Journal of Training and Development 11: 282-294. doi:10.1111/j.1468-2419.2007. 00286.x.

Watson, A. M., L. Foster Thompson, J. V. Rudolph, T. J. Whelan, T. S. Behrend, and A. L. Gissel. 2013. "When Big Brother is Watching: Goal Orientation Shapes Reactions to Electronic Monitoring During Online Training." Journal of Applied Psychology 98: 642-657. doi:10.1037/a0032002.

Wenger, E., R. McDermott, and W. M. Snyder. 2002. Cultivating Communities of Practice. Boston, MA: Harvard Business School Press.

Zhao, Y., J. Lei, B. Yan, C. Lai, and S. Tan. 2005. "What Makes the Difference? A Practical Analysis of Research on the Effectiveness of Distance Education." Teachers College Record 107: 18361884. doi:10.1111/j.1467-9620.2005.00544.x. 